\title{
Relationship between cognitive impairment and nutritional assessment on functional status in Calabrian long-term-care
}

\section{Alba Malara \\ Giovanni Sgrò \\ Chiara Caruso \\ Francesco Ceravolo \\ Giuseppe Curinga \\ Grazia Francesca Renda \\ Fausto Spadea \\ Michele Garo \\ Vincenzo Rispoli}

Scientific Committee of the National Association of Third Age Structures (ANASTE) Calabria, Italy

\section{Video abstract}

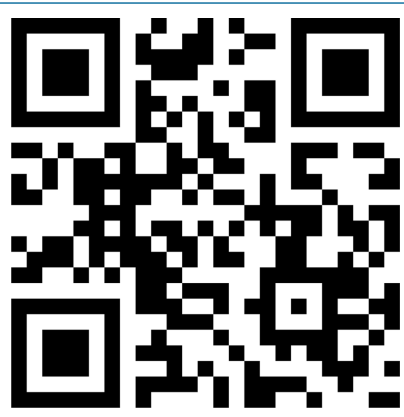

Point your SmartPhone at the code above. If you have a $Q R$ code reader the video abstract will appear. Or use: http://dvpr.es/liA665v
Correspondence: Alba Malara Via Torre $\mathrm{N}^{\circ} 8 \mathrm{I}$,

88046 Lamezia Terme, CZ, Italy

Tel +390968 442727

Fax +390968 400478

Email alba.doc@tiscali.it
This article was published in the following Dove Press journal:

Clinical Interventions in Aging

9 January 2014

Number of times this article has been viewed

Objective: The interaction between dementia and nutritional state is very complex and not yet fully understood. The aim of the present study was to assess the interaction between cognitive impairment and nutritional state in a cohort of residential elderly in relationship with functional condition of patients and their load of assistance in long-term-care facilities of the National Association of Third Age Structures (ANASTE) Calabria.

Methods: One hundred seventy-four subjects (122 female and 52 male) were admitted to the long-term-care ANASTE Calabria study. All patients underwent multidimensional geriatric assessment. Nutritional state was assessed with the Mini Nutritional Assessment (MNA), whereas cognitive performance was evaluated by the Mini-Mental State Examination (MMSE). The functional state was assessed by Barthel Index (BI) and Activity Daily Living (ADL). The following nutritional biochemical parameters were also evaluated: albumin, cholesterol, iron, and hemoglobin. All patients were reassessed 180 days later.

Results: A severe cognitive impairment in MMSE performance was displayed in $49.7 \%$ patients, while $39.8 \%$ showed a moderate deficit; $6.9 \%$ had a slight deficit; and $3.4 \%$ evidenced no cognitive impairment. In MNA, 30\% of patients exhibited an impairment of nutritional state; $56 \%$ were at risk of malnutrition; and 14\% showed no nutritional problems. Malnutrition was present in $42 \%$ of patients with severe cognitive impairment, but only $4 \%$ of malnourished patients showed moderate cognitive deficit. The statistical analysis displayed a significant correlation between MNA and MMSE $(P<0.001)$, as did MMSE correlated with Activity Daily Living $(P<0.001)$ and BI $(P<0.05)$. MNA correlated with BI $(P<0.001)$ and albumin $(P<0.001)$. The follow-up showed a strong correlation between cognitive deterioration and worsening of nutritional state $(P<0.005)$ as well as with the functional state $(P<0.05)$ and mortality $(P<0.01)$.

Conclusion: The present study clearly shows that malnutrition may play an important role in the progression of cognitive loss.

Keywords: nutritional state, dementia, elderly, nursing home, disability

\section{Introduction}

The elderly are particularly vulnerable to nutritional change deficits. Malnutrition in elderly patients has a large number of negative consequences on health: it can often influence the prognosis of different pathologies, reduce health-related quality of life, and increase morbidity/mortality and hospital admissions. ${ }^{1,2}$ Malnutrition is common among residents in hospitals and nursing homes. In Europe, considering the time of admission to hospital, prevalence of malnutrition ranges from $10 \%-80 \%$, with an average value of $35 \%$ upon hospital admission, and it tends to worsen in most cases during hospitalization, while, in long-term-care (LTC) settings and in nursing homes, the average prevalence is $30 \%{ }^{3}$ The malnutrition prevalence has been reported to be $3 \%-5 \%$ of 
free-living older adults ${ }^{4,5}$ and $21.3 \%$ in home care patients. ${ }^{6}$ The etiology is multifactorial and involves physiological aging $^{7}$ and socioeconomic and psychological factors, ${ }^{8}$ as well as comorbid conditions typical of the elderly. ${ }^{9,10}$ Dementia is itself a risk factor for malnutrition. A recent study shows that the nutritional state of institutionalized dementia patients is worse than those not institutionalized of the same age and with a normal cognitive state or mild cognitive impairment. ${ }^{11}$ The relationship between weight loss and dementia is complex and not completely clear; in fact, weight loss can be different according to the type of dementia, the stage of the disease, and the living situation of the patients. Studies examining food intake in the dementia population report varying results regarding the extent of weight loss and the adequacy of diet and/or energy intake. ${ }^{12,13}$ Grundman et al found a significant association between low body mass index and cerebral cortex atrophy in the areas involved in control of eating behavior among patients with Alzheimer's disease (AD). ${ }^{14}$ White et al explored the association between $\mathrm{AD}$ and weight changes, studying 362 subjects affected by AD and 317 control subjects for 2 years. ${ }^{15}$ They found that almost twice as many patients with AD lost more than $\geq 5 \%$ total body weight compared to controls, and that patients with more severe forms of $\mathrm{AD}$ are six to seven times more likely to suffer progressive loss of weight. ${ }^{15}$ Poor nutritional status further undermines the functional state of dementia promoting musculoskeletal damage (sarcopenia and osteopenia), causing immunosuppression and, ultimately, decreases in respiratory and cardiac capacity. ${ }^{16}$ Malnutrition becomes more evident in later stages of the disease when dysphagia or complications, such as pressure ulcers, repeated infections, and immobility syndrome, that further worsen the nutritional state of the patient, occur. ${ }^{17}$ About $78 \%$ of residents in nursing homes and extensive rehabilitation organizations associated with the National Association of Third Age Structures (ANASTE) Calabria (an Italian association of nursing home and rehabilitation to care for third age) were found to suffer from cognitive deterioration of different etiologies and gravities, of which $52 \%$ had severe dementia. Diagnostic reevaluation of these patients, according to the criteria of the National Institute of Neurological and Communicative Disorders and Stroke and the Alzheimer's Disease and Related Disorders Association (NINCDS-ADRDA), ${ }^{18}$ showed that $56.14 \%$ were suffering from AD: in particular, $45.45 \%$ met the criteria for possible $\mathrm{AD} ; 28.12 \%$ met the criteria for probable $\mathrm{AD}$; and $37.5 \%$ met the criteria for probable-uncertain AD. ${ }^{19}$ Few studies have focused on the relationship between patients' nutritional states and severity of dementia, comorbidity and functional state in institutionalized demented. ${ }^{16}$ Patients suffering from malnutrition have an increased need for nursing care due to the increased incidence of complications and reduced quality of life. ${ }^{20}$ The need for assistance may be calculated by an index of case mix and load assistance, expressed in minutes of assistance/day and multidisciplinary team in LTC. ${ }^{21,22}$

The purpose of the present study was to investigate the relationship between cognitive deficit and nutritional state in a cohort of elderly residents in LTC on functional state and the load of assistance.

\section{Materials and methods Study setting}

A network of LTC facilities for the care of frail elderly, consisting of nursing homes and extensive rehabilitation organizations, operates in Calabria, Italy. Access to these facilities is regulated according to the guidelines provided by the Calabria region (DGR 685/2002, DGR 695/2003, LR 29/2008, DGR 3137/1999). The present study was a 6-month observational, descriptive study carried out on residents across ten ANASTE Calabria nursing homes in January 2010. The customary care practices provided to all patients who belong to ANASTE Calabria LTC facilities were conducted throughout the study. At the moment of admission to LTC, informed consent of the patients and/or their caregiver was acquired for daily care practices and use of their personal data. All patients underwent multidimensional geriatric assessment. Baseline and follow-up data comprised a battery of validated indices chosen to establish an overview of health state.

\section{Subjects and measurements}

A sample of 174 residents, 122 female (70.1\%) and 52 male (29.8\%), was subjected to multidimensional and multidisciplinary evaluation. All patients underwent clinical, neuropsychological, and biological investigations. The diagnosis of dementia was investigated in an interview covering detailed personal and family history and was subsequently confirmed by the administration of psychometric tests. All patients fulfilled the criteria for dementia as described in the Diagnostic and Statistical Manual of Mental Disorders, Fourth Edition, Text Revision (DSM-IV-TR). ${ }^{23}$ Cognitive evaluation was conducted by a neuropsychologist who used Folstein et al's Mini-Mental State Examination (MMSE). ${ }^{24}$ The patients were assessed as affected by severe, moderate, or slight cognitive impairment, based on MMSE scores (0-10, 10-20, and 20-23, respectively). Functional state was evaluated with the use of the Activity Daily Living (ADL) ${ }^{25}$ and Barthel Index (BI), ${ }^{26}$ in each of which a lower score indicates a worse functional state. The affective state was scored using the Geriatric Depression Scale (GDS), in which a high score $(>6)$ denotes a depressive 
state. ${ }^{27}$ Comorbidity was examined according to the indices of severity and complex comorbidity of Cumulative Illness Rating Scale (CIRS), in which higher scores indicate greater comorbidity. ${ }^{28}$ Health care need was calculated in terms of minutes of assistance through evaluation by Resource Utilization Groups (RUG)-III. ${ }^{22}$ Finally, the number of different medications per patient was determined. The nutritional state evaluation included several biochemical values in serum, albumin $(\mathrm{g} / \mathrm{dL})$, cholesterol $(\mathrm{mg} / \mathrm{dL})$, iron $(\mu \mathrm{g} / \mathrm{dL})$, and hemoglobin $(\mathrm{g} / \mathrm{dL})$, quantified by the Mini Nutritional Assessment (MNA) ${ }^{29,30}$ The MNA has been previously validated for screening and assessment of malnutrition in older people. Harris et al noted that the MNA test demonstrates $80 \%$ sensitivity and $90 \%$ specificity. ${ }^{31}$ Patients are classified in MNA as follows: normal nutritional state (score of $<24$ to $>30$ ); at risk of malnutrition (score of 17-23.5); and malnutrition (score of $<17$ ). Of the enrolled patients, 142 were reassessed after 6 months by MMSE and MNA only.

\section{Statistical analysis}

Data were collected from a database generated and managed by ANASTE Calabria from 2010. Data are presented as mean \pm standard error of mean (SEM) and were analyzed using GraphPad Prism statistics software package (version 6; GraphPad Software, Inc., La Jolla, CA, USA). Comparison was performed between multiple parameters using analysis of variance (ANOVA), while categorical variables were compared using Wilcoxon-Mann signed-rank test for multiple comparisons. Spearman's rank correlation coefficient and Student's $t$-test were used to find a correlation between different measures. Tests with $P<0.05$ were considered statistically significant.

\section{Results}

At baseline, the average age was 74 years for men and 81 for women. Patients scored $1.4 \pm 2.4$ in ADL performance and $28 \pm 13$ in $\mathrm{BI}$ (mean \pm standard deviation). Calculation of complex comorbidity, according to the CIRS, showed an average number of illnesses of $2.99 \pm 2.2$, with severity of comorbidity averaging $2.04 \pm 1.9$. Only 59 patients (34\%) were subjected to GDS and showed no depressive state $(4.73 \pm 3.3)$; it was not possible to administer GDS in 115 patients (64\%) because of cognitive impairment. The assessment of care need expressed in minutes of assistance according to RUG-III showed an average burden of 327.2 minutes/day of care for patient. The enrolled patients took an average of $5.7 \pm 3.5$ different medications (Table 1). The 86 patients of the total number (49.7\%) had a severe cognitive impairment as assessed by MMSE; 69 patients (39.8\%) showed a moderate deficit; 12 patients $(6.9 \%)$
Table I Population and measurement characteristics

\begin{tabular}{ll}
\hline Subjects & $\mathbf{n}$ \\
\hline Males & $52(\mathrm{n})$ \\
Females & $122(\mathrm{n})$ \\
Average age (years) & 74 \\
$\quad$ Males & $8 \mathrm{I}$ \\
$\quad$ Females & Mean + standard error \\
Measures & of the mean \\
& $2.99 \pm 2.2$ \\
\hline Complex Comorbidity Index ${ }^{28, a}$ & $2.04 \pm 1.99$ \\
Severity of Comorbidity Index ${ }^{28, a}$ & $1.4 \pm 2.4$ \\
Activities of Daily Living & $28 \pm 13$ \\
Barthel Index & \\
Geriatric Depression Scale ${ }^{27}$ & $4.73 \pm 3.3$ \\
Number of drugs & $5.7 \pm 3.5$ \\
Medium care need (minutes/day) & 327.2 \\
\hline Notes: alndex of the Cumulative Illness Rating Scale; ${ }^{28}$ ber person, as per Resource
\end{tabular}
Utilization Groups-1II. ${ }^{22}$

exhibited slight deficit; and only six patients (3.4\%) presented no cognitive impairment (Figure 1; Table 2). Twenty-five patients (14\%) had no nutritional problems as assessed with MNA; 97 patients (56\%) were at risk of malnutrition; and 52 patients $(30 \%)$ had an impaired nutritional state (Figure 2; Table 2). Among patients with severe cognitive impairment, 36 (42\%) presented with malnutrition; 48 were at risk of malnutrition; and nine (10\%) showed no nutritional impairment. At follow-up, 142 patients, 47 male (33\%) and 95 female (67\%), were assessed. Seventy-eight patients (55\%) showed a severe cognitive impairment in MMSE; 52 patients (36\%) showed a moderate deficit; and ten (19\%) had a slight deficit. In MNA, 32 patients $(22 \%)$ demonstrated no nutritional problems; $69(48 \%)$ were at risk of malnutrition; and $41(29 \%)$ had an impairment of nutritional state (Table 2).

The linear regression analysis showed a statistically significant correlation between MNA and MMSE ( $r=0.39$; $P<0.001)$ (Figure 3; Table 2), MMSE and ADL $(r=0.39$; $P<0.001)$, MMSE and BI $(r=0.15 ; P<0.05)$, and MNA and $\mathrm{BI}(r=0.27 ; P<0.001)$. MNA in our study does not correlate

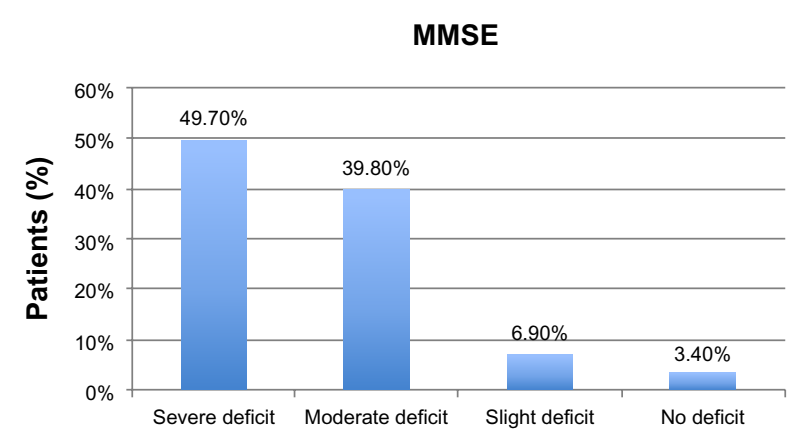

Figure I Evaluation of cognitive impairment at baseline using Mini-Mental State Examination (MMSE). 
Table 2 Evaluation of and correlation between nutritional state and cognitive impairment

\begin{tabular}{llllll}
\hline Test & T0 (start) & & \multicolumn{2}{c}{ TI (6 months) } \\
\cline { 2 - 3 } & $\mathbf{n}$ & $\%$ & & $\mathbf{n}$ & $\%$ \\
\hline MMSE & & & & & \\
$\quad<10$ & 86 & 49.7 & & 78 & 55 \\
$>10<20$ & 69 & 39.8 & & 52 & 36 \\
$>20$ & 12 & 6.9 & & 10 & 19 \\
MNA & & & & \\
$<17$ & 52 & 30 & & 41 & 29 \\
$>17<23$ & 97 & 56 & & 69 & 48 \\
$>23$ & 25 & 14 & & 32 & 22 \\
MMSE vs MNA & $r=0.39$ & & & $r=0.37$ & \\
& $P<0.001$ & & & $P<0.01$ & \\
\hline
\end{tabular}

Abbreviations: MMSE, Mini-Mental State Examination; MNA, Mini Nutritional Assessment; vs, versus.

with blood tests evaluated except with albumin $(r=0.59$; $P<0.001)$. There was no statistically significant correlation between cognitive impairment, nutritional state, comorbidity, and use of drugs, but there was a weakly significant trend between severe cognitive impairment, impaired nutritional state, and care need in minutes of assistance. Follow-up at 6 months confirmed a statistically significant correlation between MNA and MMSE $(r=0.37 ; P<0.01)$ (Figure 3; Table 2). In the malnourished group, there was no correlation between MMSE and MNA $(r=0.25 ; P>0.05)$, whereas there was a significant correlation between the group with severe cognitive deficit and the group with moderate cognitive impairment $(r=0.33 ; P<0.05)$.

These results indicate that the improvement of nutritional condition is accompanied by an improvement of cognitive function. The analysis with the rank correlation coefficient for the Spearman and Student's $t$-test showed a strong correlation between levels of cognitive deterioration and worsening of nutritional state $(P<0.05)$, functional state $(P<0.05)$, and mortality $(P<0.01)$.

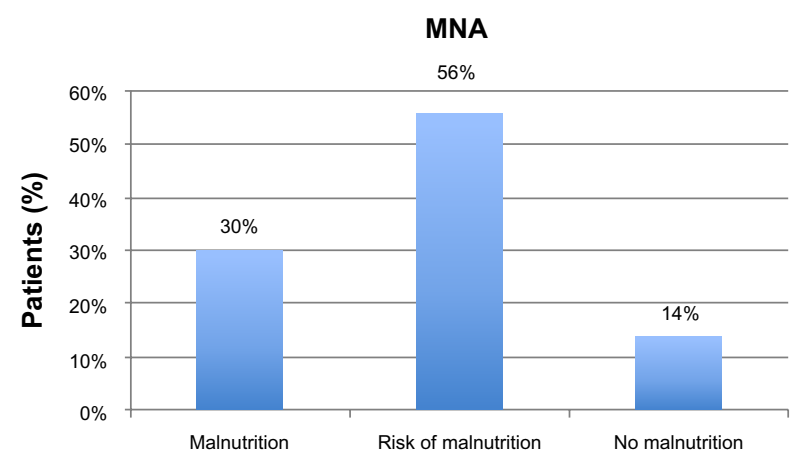

Figure 2 Evaluation of nutritional state at baseline using Mini Nutritional Assessment (MNA).

\section{Discussion}

Prevalence of malnutrition and risk of malnutrition in institutionalized elderly patients with dementia is high and increases with progression of disease. The MNA, standardized for the elderly population, ${ }^{30}$ is the preferred tool for nutritional assessment in LTC associated with ANASTE Calabria, although, in the literature, authors report different opinions about its use in institutionalized elderly with dementia. ${ }^{32,33}$ The results of the present study confirm that patients affected by serious cognitive impairment are characterized by a poor nutritional state, a serious impairment of functional conditions, and increased mortality. This disorder does not appear to be associated with increased comorbidity and/or use of drugs. Previous studies have shown an inverse correlation between cognitive impairment and comorbidity in a large sample of patients admitted to nursing homes: $:^{34,35}$ it was found that the prevalence of defined cardiovascular diseases, such as hypertension, decreased in relation to increased dementia severity, ${ }^{36}$ although other authors disagree: the comorbidity is inversely correlated with the degree of cognitive impairment. ${ }^{37}$ Moreover, some studies have shown a relationship between nutritional state and comorbidities. ${ }^{38}$ In the present study, such an association was not confirmed, although we found a trend towards a worsening of health conditions in malnourished subjects. Generally, malnourished subjects show a greater functional impairment in ADL and higher care need..$^{39}$ Our study results are in line with the existing literature; in most studies, disability has been found to be associated with both anthropometric as well as biochemical parameters related to malnutrition. ${ }^{40}$ Cereda et $a l^{41}$ showed that a bad functional status correlates with a low MNA score. Moreover, in the present study, no correlation was found between mood disorder and nutritional state, while, in another study, depression is considered a risk factor for malnutrition in institutionalized elderly. ${ }^{42}$ Since $52 \%$ of malnourished patients suffered from severe cognitive impairment in the present study, it was not possible to administer the GDS. The care need in these patients, calculated by RUG-III and expressed in minutes of assistance, shows a weak correlation with the prevalence of malnutrition, although it does not reach statistical significance. These data can be explained by considering that the admission of patients in nursing homes follow criteria of homogeneity of utilization of resources. ${ }^{22}$ Patients were reevaluated after 6 months, and increased mortality was found in malnourished subjects when compared with patients who had a better nutritional status. It is well known that, in a geriatric population, loss of $>4 \%$ body weight is an independent factor of morbidity and mortality. ${ }^{43}$ The inci- 


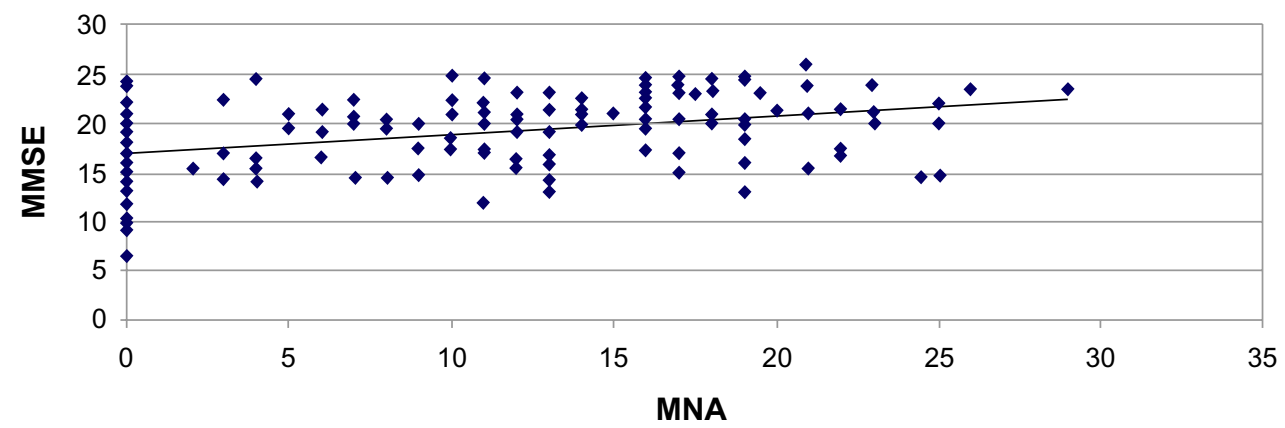

Figure 3 Correlation between nutritional state (Mini Nutritional Assessment [MNA]) and cognitive impairment (Mini-Mental State Examination [MMSE]) at 6-month follow-up.

dence of medical problems associated with malnutrition in elderly people in nursing homes is $27 \%$, whereas it is about $16 \%$ in patients who are well nourished, although mortality is three times higher in the former. ${ }^{44}$ In elderly patients, the effectiveness of nutritional interventions is reduced and recovery of malnutrition is difficult to achieve. ${ }^{45}$ In patients with dementia, a state of malnutrition must be prevented or at least improved by an early and appropriate intervention strategy. ${ }^{46,47}$ The results of the present study show that it is necessary to set appropriate nutritional interventions in patients with mild-to-moderate dementia; in fact, these patients have more opportunities for therapeutic response than patients suffering from severe dementia. In ANASTE Calabria LTCs, the multidisciplinary team is trained to carry out the assessment of nutritional state. This team is also trained to identify as risk factors for malnutrition both the cognitive impairment and worsening of functional state.

\section{Conclusion}

Malnutrition plays an important role in the progression of cognitive decline; early recognition and treatment of malnutrition or risk of malnutrition are important preventive measures to increase the quality of care and quality of life of patients with dementia.

\section{Acknowledgment}

Special thanks to Mrs Rosa Procopio for her kind revision of the manuscript for English style and grammar. This work was conducted in the following LTC: Casa Protetta "Madonna del Rosario," Lamezia Terme (CZ); RSA "Villa Elisabetta," Cortale (CZ); RSA “San Domenico” Lamezia Terme (CZ); Centro di Riabilitazione Estensiva a ciclo continuativo "San Domenico" Lamezia Terme (CZ); Casa Protetta "San Domenico," Palermiti (CZ); RSA "Santa Maria del Monte" San Sostene (CZ); RSA "Ippolito Dodaro," Falerna (CZ); RSA “Casa Amica," Fossato Serralta (CZ); Centro di
Riabilitazione Estensiva a ciclo continuativo "Villa Vittoria" (RC); RSA "Villa Vittoria" (RC).

\section{Disclosure}

The authors report no conflicts of interest in this work.

\section{References}

1. Phillips MB, Foley AL, Barnard R, Isenring EA, Miller MD. Nutritional screening in community-dwelling older adults: a systematic literature review. Asia Pac J Clin Nutr. 2010;19(3):440-449.

2. Arija V, Martín N, Canela T, et al. Nutrition education intervention for dependent patients: protocol of a randomized controlled trial. BMC Public Health. 2012;12:373.

3. De Luis DA, López Mongil R, Gonzalez Sagrado M, et al; Group Novomet. Nutritional status in a multicenter study among institutionalized patients in Spain. Eur Rev Med Pharmacol Sci. 2011;15(3): 259-265.

4. Aukner C, Eide HD, Iversen PO. Nutritional status among older residents with dementia in open versus special care units in municipal nursing homes: an observational study. BMC Geriatr. 2013;13:26.

5. Visvanathan R, Newbury JW, Chapman I. Malnutrition in older people. Screening and management strategies. Aust Fam Physician. 2004;33:799-805.

6. Jiménez Sanz M, Sola Villafranca JM, Pérez Ruiz C, et al. [Study of the nutritional status of elders in Cantabria]. Nutr Hosp. 2011;26:345-354. Spanish.

7. St-Onge MP, Gallagher D. Body composition changes with aging: the cause or the result of alterations in metabolic rate and macronutrient oxidation? Nutrition. 2010;26(2):152-155.

8. Jürschik P, Nuin C, Pera M, et al. Factores sociodemográficos y psicosociales que influyen en el estado nutricional de los mayores de 65 años de diferentes niveles asistenciales. [Sociodemographic and psychosocial factors that influence the nutritional status of over 65 different levels of care]. Gerokomos. 2005;16(1):27-36. Spanish.

9. Guérin O, Andrieu S, Schneider SM, et al. Different modes of weight loss in Alzheimer disease: a prospective study of 395 patients. Am J Clin Nutr. 2005;82:435-441.

10. Guérin O, Andrieu S, Schneider SM, et al. Characteristics of Alzheimer's disease patients with a rapid weight loss during a six-year follow-up. Clin Nutr. 2009;28:141-146.

11. Zekry D, Herrmann FR, Grandjean R, et al. Demented versus nondemented very old inpatients: the same comorbidities but poorer functional and nutritional status. Age Ageing. 2008;37:83-89.

12. Wang PN, Yang CL, Lin KN, Chen WT, Chwang LC, Liu HC. Weight loss, nutritional status and physical activity in patients with Alzheimer's disease. J Neurol. 2004;251:314-320.

13. Poehlman ET, Dvorak RV. Energy expenditure, energy intake, and weight loss in Alzheimer disease. Am J Clin Nutr. 2000;71(2):650S-655S. 
14. Grundman M, Corey-Bloom J, Jernigan T, Archibald S, Thal LJ. Low body weight in Alzheimer's disease is associated with mesial temporal cortex atrophy. Neurology. 1996;46:1585-1591.

15. White H, Pieper C, Schmader K, Fillenbaum G. A longitudinal analysis of weight change in Alzheimer's disease. J Am Geriatr Soc. 1997; 45:531.

16. Camina Martín MA, Barrera Ortega S, Domínguez Rodríguez L, Couceiro Muiño C, de Mateo Silleras B, Redondo del Río MP. [Presence of malnutrition and risk of malnutrition in institutionalized elderly with dementia according to the type and deterioration stage]. Nutr Hosp. 2012;27(2):434-440. Spanish.

17. Camina Martín MA, de Mateo Silleras B, Carreño Enciso L, de la Cruz Marcos S, Miján de la Torre A, Redondo del Río MP. [Changes in body composition in relation to the stage of dementia in a group of institutionalized elderly]. Nutr Hosp. 2013;28(4):1093-1101. Spanish.

18. McKhann G, Drachman D, Folstein M, Katzman R, Price D, Stadlan EM. Clinical diagnosis of Alzheimer's disease: report of the NINCDS-ARDRA Work Group under the auspices of Department of Health and Human Services Task Force on Alzheimer's Disease. Neurology. 1984;34:934-994.

19. Malara A, Sgrò G, Capomolla S, et al. Coordinamento Scientifico ANASTE Calabria. Rivalutazione diagnostica e funzionale della malattia di Alzheimer nelle strutture residenziali ANASTE Calabria. G Gerontol. 2010;LVIII/6;315-595. Italian.

20. Meijers JM, Halfens RJ, Wilson L, Schols JM. Estimating the costs associated with malnutrition in Dutch nursing homes. Clin Nutr. 2012;31(1):65-68.

21. Carpenter I, Perry M, Challis D, Hope K. Identification of registered nursing care of residents in English nursing homes using the Minimum Data Set Resident Assessment Instrument (MDS/RAI) and Resource Utilisation Groups version III (RUG-III). Age Ageing. 2002;32: 279-285.

22. Malara A, Caruso C, Ceravolo F, et al. Scientific Committee Anaste Calabria. Utilization of RUG-III (Resource Utilization Groups-III) classification system in the Calabrian nursing homes. G Gerontol. 2008;56:605-610.

23. Diagnostic and Statistical Manual of Mental Disorders, Fourth Edition, Text Revision (DSM-IV-TR). Washington, DC: American Psychiatric Association; 2000.

24. Folstein MF, Folstein SE, McHugh PR. "Mini-mental state." A practical method for grading the cognitive state of patients for the clinician. J Psychiatr Res. 1975;12:189-198.

25. Katz S. Assessing self-maintenance: activities of daily living, mobility, and instrumental activities of daily living. J Am Geriatr Soc. 1983;31: 721-727.

26. Mahoney FI, Barthel DW. Functional evaluation: the Barthel Index. Md State Med J. 1965;14:61-65.

27. Sheikh JI, Yesavage JA. Geriatric Depression Scale (GDS): recent evidence and development of a shorter version. In: Brink TL, editor. Clinical Gerontology: A Guide to Assessment and Intervention. New York, NY: The Haworth Press; 1986:165-173.

28. Parmelee PA, Thuras PD, Katz IR, Lawton MP. Validation of the Cumulative Illness Rating Scale in a geriatric residential population. J Am Geriatr Soc. 1995;43:130-137.

29. Guigoz Y, Vellas BJ, Garry PJ. Assessing the nutritional status of the elderly. The Mini Nutritional Assessment as part of the geriatric evaluation. Nutr Rev. 1996;54:59-65.
30. Vellas B, Guigoz Y, Baumgartner M, Garry PJ, Lauque S, Albarede JL. Relationships between nutritional markers and the mini-nutritional assessment in 155 older persons. J Am Geriatr Soc. 2000;48: $1300-1309$.

31. Harris DG, Davies C, Ward H, Haboubi NY. An observational study of screening for malnutrition in elderly people living in sheltered accommodation. J Hum Nutr Diet. 2008;21(1):3-9.

32. Cuesta D, Medina L, Salvador MI, Avellana JA. Changes in body composition in relation to the state of dementia in a group of institutionalized elderly. Nutr Hosp. 2013; 28(3): 1093-1101. Spanish.

33. Tarazona Santabalbina FJ, Belenguer Varea A, Doménech Pascual JR, et al. [Validation of MNA scale score as a nutritional risk factor in institutionalized geriatric patients with moderate and severe cognitive impairment]. Nutr Hosp. 2009;24(6):724-731. Spanish.

34. Landi F, Onder G, Cattel C; Silvernet-HC Study Group. Functional status and clinical correlates in cognitively impaired community-living older people. J Geriatr Psychiatry Neurol. 2001;114:21-27.

35. Donini LM, Neri B, De Chiara S, Poggiogalle E, Muscaritoli M. Nutritional care in a nursing home in Italy. PLoS One. 2013;8(2): e55804.

36. Hogan DB, Ebly EM, Rockwood K. Weight, blood pressure, osmolarity, and glucose levels across various stages of Alzheimer's disease and vascular dementia. Dement Geriatr Cogn Disord. 1997;8: $147-151$.

37. Van Dijk PT, Dippel DW, Van Der Meulen JH, Habbema JD. Comorbidity and its effect on mortality in nursing home patients with dementia. J Nerv Ment Dis. 1996;184:180-187.

38. Donini LM, De Felice MR, Savina C, et al. Predicting the outcome of long-term care by clinical and functional indices: the role of nutritional status. J Nutr Health Aging. 2011;15(7):586-592.

39. Wojszel ZB. Determinants of nutritional status of older people in long-term care settings on the example of the nursing home in Białystok. Adv Med Sci. 2006;51:168-173.

40. Oliveira MR, Fogaça KC, Leandro-Merhi VA. Nutritional status and functional capacity of hospitalized elderly. Nutr J. 2009;8:54.

41. Cereda E, Valzolgher L, Pedro C. Mini nutritional assessment is a good predictor of functional status in institutionalised elderly at risk of malnutrition. Clin Nutr. 2008;27(5):700-705.

42. Boström AM, Van Soest D, Kolewaski B, Milke DL, Estabrooks CA. Nutrition status among residents living in a veterans' long-term care facility in Western Canada: a pilot study. J Am Med Dir Assoc. 2011;12(3):217-225.

43. Guyonnet S, Nourhashemi F, Andrieu S. A prospective study in the nutritional status of Alzheimer's patients. Arch Gerontol Geriatr. 1998; 255-262.

44. Correia CM, Waitzberg DL. The impact of malnutrition on morbidity, mortality, length of hospital stay and costs evaluated through a multivariate model analysis. Clin Nutr. 2003;22:235-239.

45. Kubrak C, Jensen L. Malnutrition in acute care patients: a narrative review. Int J Nurs Stud. 2007;44:1036-1054.

46. Pirlich M, Schütz T, Norman K, et al. The German hospital malnutrition study. Clin Nutr. 2006;25:563-572.

47. Rivière S, Gillette-Guyonnet S, Voisin T, et al. A nutritional education program could prevent weight loss and slow cognitive decline in Alzheimer's disease. J Nutr Health Aging. 2001;5:295-299.
Clinical Interventions in Aging

\section{Publish your work in this journal}

Clinical Interventions in Aging is an international, peer-reviewed journal focusing on evidence-based reports on the value or lack thereof of treatments intended to prevent or delay the onset of maladaptive correlates of aging in human beings. This journal is indexed on PubMed Central, MedLine, the American Chemical Society's 'Chemical Abstracts
Dovepress

Service' (CAS), Scopus and the Elsevier Bibliographic databases. The manuscript management system is completely online and includes a very quick and fair peer-review system, which is all easy to use. Visit $\mathrm{http}: / /$ www.dovepress.com/testimonials.php to read real quotes from published authors. 